\title{
Starch Isolation from Different Cereals with Variable Amylose/Amylopectin Ratio and Its Morphological Study Using SEM and FT-IR
}

Vivek Chandra Verma ${ }^{1}$, Anil Kumar ${ }^{2}$, M.G.H. Zaidi ${ }^{3}$, A.K. Verma ${ }^{1}$, J.P. Jaiswal ${ }^{4}$, D.K. Singh ${ }^{5}$, Archana Singh ${ }^{1}$ and Sanjeev Agrawal ${ }^{1 *}$

${ }^{1}$ Department of Biochemistry, ${ }^{2}$ Department of Molecular Biology and Genetic Engineering

${ }^{3}$ Department of Chemistry, ${ }^{4}$ Department of Genetics and Plant Breeding, ${ }^{5}$ Department of Agronomy, GBPUA\&T, Pantnagar - 263145, India

*Corresponding author

\section{A B S T R A C T}

Starches from the wheat (UP262, PBW343), rice (PB2, PD19) and millets (Finger millet VL Mandua-352, Barnyard millet VL Madira-207, Foxtail millet DHFT-109-3) were isolated by alkali extraction method and characterized for morphologically and

\section{Keywords}

Amyloseamylopectin, Rice, Wheat, Millets, Starch, SEM, FT-IR

Article Info

Accepted: 04 September 2018 Available Online: 10 October 2018 biochemical properties. The morphological properties of starch granules were studied by scanning electron microscope. The infrared spectroscopy is sensitive to structural changes on starch macromolecule, such as helicoidal chain conformation, crystallinity, retrogradation and water content. Starch yield was found maximum in rice followed by wheat and millets. High value of amylose-amylopectin ratio indicates low glycemic index. Amylose content is important for food processing in the industry and for quality. The amylose content (\%) was found significant in all cultivars. The amylose content (\%) was found maximum in rice (PB2, PD19) and wheat (UP262) followed by PBW343 (Wheat) and finger millet. The amylose content in millet varies from 31-33\%. Total starch content ranged from $57-70 \%$ in cereals in the present study. Total starch content was found maximum in rice followed by wheat and millets. Total starch content in rice (PB2 \& PD19) was found $67 \%$ and $70 \%$ respectively. The proximate content of total starch in barnyard millet (58\%), finger millet (57\%) and foxtail millet $(59 \%)$ was found in the present study. Scanning electron microscopy (SEM) has been a useful tool for investigating the microstructures of cereal grains and derived products.

\section{Introduction}

Starch is the most abundant storage reserve carbohydrate found in many different plant organs, including seeds, fruits, tubers and roots. It is used as a source of energy during periods of dormancy and re-growth (Roper, 2002). Starch is versatile and useful polymer because of ease of availability with which its 
physiochemical properties can be altered through chemical, physical and enzymatic treatment (Jobling, 2004). Starch is important ingredients in various food systems as thickening, gelling and binding agents. It imparts texture to various foodstuffs (Thebaudin et al., 1998). Starch is made up of two polymers of D-glucose: amylose and amylopectin. Amylose is fundamentally a linear molecule of $\alpha-1$, 4-linked glucan and occupies approximately $15-30 \%$ of starch, while amylopectin, the major component (70$85 \%$ ), is a larger molecule with highly $\alpha-1,6$ branched chains. Amylose has a molecular weight ranging $10^{5}-10^{6}$ and degree of polymerization is nearly $1000-10,000$ glucose units. Amylopectin is a much larger polymer, with a molecular weight about $10^{8}$ and a degree of polymerization is much higher than amylose (Copeland et al., 2009). Starch granules are thought to have alternative layers of crystalline and amorphous regions constructed by amylopectin and amylose (Srichuwong et al., 2005). Amylose and amylopectin make up $98-99 \%$ of the dry weight of native granules, with the remainder comprising small amounts of lipids, minerals, and phosphorus in the form of phosphates esterified to glucose hydroxyls. Starch granules range in size from 1 to $100 \mu \mathrm{m}$ diameters and shape of polygonal, spherical, lenticular, and can vary greatly in content, structure and organization of the amylose and amylopectin molecules, the branching architecture of amylopectin, and the degree of crystallinity (Lindeboom et al., 2004). Wang et al., (1998) reported that chains of amylopectin are organized into double helices and form crystalline structures. Scanning electron microscopy (SEM) is frequently used because of the short wavelength of the electron beam, which makes it possible to determine granule size more accurately. The resolution possible with SEM also provides a more detailed perspective on granule surface characteristics and granule morphology
(Chmelik, 2001). Scanning electron microscopy (SEM) has been used to relate granule morphology to starch genotype (Fannon et al., 1992a). SEM has also been used to relate paste structures to paste properties (Fannon and BeMiller, 1992; Fannon et al., 1992b). Hoover (2001) reported that the cereal starch exhibit the A-type crystalline structure whereas, the tuber starches show the B-form and legumes, the mixed state pattern ' $C$ '. Starch granule size, amylose/amylopectin ratio and various physical and chemical characteristics reveals the starch paste behaviours in aqueous system (Madsen and Christensen, 1996). The amylose content of the starch granules varies with the botanical source of the starch and is affected by the climatic conditions and soil type during growth (Morison and Azudin, 1987). Kim and Huber (2008) reported that wheat endosperm contains A-type and B-type starch granules, showing a bimodal granule size. A-type granules are bigger $(10-35 \mu \mathrm{m})$ and disk- or lenticular-shaped whereas B-type granules are smaller $(<10 \mu \mathrm{m})$ and spherical or angular (Evers, 1973). Edwards et al., (2002) reported that higher proportion of smaller granules increased dough elastic properties. Hence morphology study using SEM reveals the quality of starch isolated from different botanical origin. Granules size $(<10 \mu \mathrm{m})$ bind more water, which likely increases dough stiffness and reduces the elasticity (Huang and Lai, 2010). It was reported that the qualities of both dried and cooked starch noodles made from small-sized granule fractions are much better than those made from large-sized granule fractions (Chen et al., 2003) but granule size (about $12 \mu \mathrm{m}$ ) can increase bread weight (Sahlström et al., 1998). The relative amounts of amylose and amylopectin gives starch to unique physical and chemical properties which convey specific functionality (Fergason, 1994). High amylose starches have numerous industrial applications. These starches are used in fried snack products to 
create crisp, evenly browned snacks. An added bonus of high amylose starches is that they hamper the penetration of cooking oils, which leads to a decrease in fat intake by the consumer. High amylose starches are widely used as thickeners, are strong gelling agents used in the production of jellies and, owing to their rapid setting properties, are used in the production of gum candies (Slattery et al., 2000). Therefore, the objective of the present study was to characterize the physio-chemical behaviour of starch isolated from different cultivars due to its versatile uses in the food and manufacturing industries. Starch is extensively used in the food and beverage industries as a thickener and a sweetener as well as having some manufacturing applications in the paper and textile industries.

\section{Materials and Methods}

Two cultivars of Rice grains (Oryza sativa $L$.) viz., PB2 and PD19 and Wheat grains viz., UP262 and PBW343 were procured from Department of Agronomy and Department of plant breeding and genetics, GBPUA\&T, Pantnagar, Uttarakhand respectively. Finger millet (VL Mandua-352) and Barnyard millet (VL Madira-207) grains were purchased from VPKAS, Almora, Uttarakhand. Foxtail millet (DHFT-109-3) grains were taken from ICARIndian Institute of Millet Research, Hyderabad. The grains were cleaned and ground in mixture grinder and stored properly at room temperature prior to their use in actual experiment. Other reagents and chemicals used were at minimum of analytical grade.

\section{Isolation of starch}

Starch was extracted by using alkaline extraction method of Kim et al., (2012) with some modification. In this procedure, centrifugation steps were at $5000 \mathrm{~g}$ for $10 \mathrm{~min}$ at $20^{\circ} \mathrm{C}$. Flour $(10 \mathrm{~g})$ was suspended in $60 \mathrm{ml}$ of $0.5 \% \mathrm{NaOH}$ solution and then stirred for 30 min and kept for $24 \mathrm{hr}$ at $4^{\circ} \mathrm{C}$. The upper yellowish layer was removed. After that $0.5 \%$ $\mathrm{NaOH}$ solution was added to form slurry and the alkaline slurry was centrifuged. The sediment was washed with $0.5 \% \mathrm{NaOH}$ solution and slurry was centrifuged again. This process was repeated until the yellowish layer was completely removed. The alkaline slurry was neutralised with $1.0 \mathrm{M} \mathrm{HCl}$ and centrifuged again. The resulting slurry of starch was dried in convection oven at 35$40^{\circ} \mathrm{C}$ for $48 \mathrm{~h}$ and gently passed through sieve using a mortar and pestle and stored at air tight container for future experiment.

\section{Amylose content determination}

Amylose content was determined by method described by McCready et al., (1950) with some modification. Weigh 100mg of flour and transfer into $100 \mathrm{ml}$ conical flask. Add $100 \mathrm{ml}$ $1 \mathrm{~N}$ sodium hydroxide $(\mathrm{NaOH})$ to disperse sample. Allow dispersion to vortex for $30 \mathrm{~min}$. The mixture must be smooth and free of lumps. Pipet $200 \mu \mathrm{l}$ of this solution into 100 $\mathrm{ml}$ conical flask and add distilled water (dw) to make volume $20 \mathrm{ml}$. Add 2 drops of phenolphthalein indicator and titrate with $1 \mathrm{~N}$ hydrochloric acid solution until the pink indicator colour just disappears. Add $1 \mathrm{ml}$ iodine reagent and finally make up volume 50 $\mathrm{ml}$ with distilled water and absorbance of the blue colour was measured at $620 \mathrm{~nm}$ against the reference solution. The amylose content was determined from a standard curve with amylose.

\section{Preparation of iodine reagent}

\section{Stock iodine solution}

Potassium iodide (20 g) was weighed into $100 \mathrm{ml}$ beaker together with $2.0 \mathrm{~g}$ resublimed iodine. The reagent were dissolved in the minimum of water and carefully diluted to 100 $\mathrm{ml}$ in a volumetric flask and stored in amber bottle. 


\section{Iodine reagent}

$10 \mathrm{ml}$ of stock iodine solution was pipetted into a volumetric flask and diluted to $100 \mathrm{ml}$ with distilled water.

\section{Total starch determination}

Total starch was determined by method adopted from Dubois et al., (1956) with some modification. Weigh $100 \mathrm{mg}$ sample and crushed in $5 \mathrm{ml}$ ethanol (80\%). After crushing the contents were filtered through Whatman filter paper.

\section{Extraction of total starch}

The residue left on filter paper is dried. Samples were refluxed for $1 \mathrm{~h}$ with $2 \mathrm{ml}$ distilled water in $95^{\circ} \mathrm{C}$ water bath.

Add $2 \mathrm{ml}$ of $9.2 \mathrm{~N} 70 \%$ perchloric acid and shake well for 15 minute and make up volume $10 \mathrm{ml}$ with distilled water. Samples are allowed for centrifuge at 5000g for 20 minute. The supernatant is collected and the pellet is again refluxed with $2 \mathrm{ml}$ of $4.6 \mathrm{~N}$ perchloric acid. Samples are allowed for centrifuge.

The supernatant is collected in the same tube and make up volume $25 \mathrm{ml}$ with distilled water for total starch estimation.

\section{Estimation of total starch}

Supernatants were analysed for glucose, by the phenol-sulphuric acid method and concentrations determined against soluble starch as a standard. Starch content of the samples was estimated by using this formula.

Starch $(\%)=(\mathrm{OD}$ of sample/ slope of the standard curve $) *(1 / 1000) *(1 / \mathrm{W}) * 100$ $1 / 1000=$ Conversion from micrograms to milligrams;
$100 / \mathrm{W}=$ Factor to express "starch" as a percentage of flour weight; $\mathrm{W}=$ weight in milligrams

\section{Scanning electron microscopy (SEM)}

Scanning electron microscopy (SEM) micrographs was recorded with a Jeol-JSM 6601ALV (made in Japan). Starch samples were applied on an aluminium stub using double sided adhesive tape, and the starch was coated with gold (using JFC 1600 gold coater).

The micrographs were obtained with an accelerating potential of $5 \mathrm{kV}$ under high vacuum. In the present study a magnification range 500X, 1000X and 2000X was used for millets starch (Barnyard millet, Finger millet and Foxtail millet) and wheat starch (UP262 and PBW343). For rice starch, 150X, 300X and 500X magnification range was used.

\section{FT-IR}

The FT-IR spectra were obtained using FT-IR at IIT Roorkee, Uttarakhand (Perkin Elmer services). The spectra were recorded in transmission mode from 4,000 to $450 \mathrm{~cm}^{-1}$ (mid-infrared region). The sample was diluted with $\operatorname{KBr}(1: 100$, w/w) before acquisition and the background value from pure $\mathrm{KBr}$ was acquired before the sample was scanned.

\section{Statistical Analysis}

The experimental data were analysed as mean \pm standard error (SE) using Completely Randomized Design. Determinations of starch yield, amylose content and total starch content were done in triplicate. Values with different letters in the same column are significantly different with $\mathrm{p}<0.05$. One-way analysis of variance (ANOVA) was carried out using OPSTAT (O.P. Sheoran Programmer, Computer Section, CCS HAU, Hisar). 


\section{Results and Discussion}

\section{Isolation of starch from different cereals}

Two cultivars of rice grains (Oryza sativa $L$.) viz., PB2 and PD19, wheat grains viz., UP262 and PBW343, finger millet (VL Mandua-352), barnyard millet (VL Madira-207) and foxtail millet (DHFT-109-3) grains were processed in the present investigation for isolation of starch (Fig. 1) and percentage yield of obtained starch was compared (Table 1). The percentage starch yield was found significant in all cereals. The maximum starch yield (\%) was found in Pant Basmati 2 followed by Pant Dhan 19 (Rice) and UP 262 (Wheat). There are no significant differences in $\%$ starch yield of foxtail millet, finger millet and PBW343 (Wheat) eg. Comparison of means with CD@ 0.05 is same. The minimum starch yield was found in barnyard millet.

\section{Proximate analysis of amylose and total starch content}

Amylose content is important for food processing in the industry and for quality. The amylose content (\%) was found significant in all cultivars. The amylose content (\%) was found maximum in rice (PB2, PD19) and wheat (UP262) followed by PBW343 (Wheat) and finger millet. The amylose content in millet varies from $31-33 \%$. Amylose contents of the above cereals were analysed and the results are shown in Table 1. The amylose content of rice starch usually ranges from $15-$ $35 \%$ (Oko et al., 2012). Blazek and Copeland (2008) reported that $35-43 \%$ amylose was found in wheat. Total starch content ranged from $57-70 \%$ in cereals in the present study. Total starch content was found maximum in rice followed by wheat and millets. Total starch content in rice-PB2 and PD19 was found $67 \%$ and $70 \%$ respectively. Li et al., (2016) reported that total starch content in rice varies from $78-81 \%$. The proximate content of total starch in barnyard millet (58\%), finger millet $(57 \%)$ and foxtail millet $(59 \%)$ was found in the present study. Total starch in millet varies from $60-65 \%$ and it was maximum in kodo millet (Shobana et al., 2013; Devi et al., 2014). The results are shown in Table 1. Gerrano et al., (2014) reported on 22 accession of sorghum and found that total starch, amylose varies from $44-68 \%$ and $14-18 \%$ respectively. Amylose and amylopectin ratio can predict the glycemic index of rice. A high value of amylose amylopectin ratio indicates low glycemic index (Dipnaik and Kokare, 2017). Frie et al., (2003) reported that the rate of hydrolysis of starch is fast which contain high amount of amylopectin. The amylose-amylopectin ratio was determined in all cultivars viz. millet, rice and wheat. It was observed that the amyloseamylopectin ratio was found maximum in Pant Basmati 2 followed by Pant Dhan 19. In case of wheat the ratio was found maximum in UP 262 followed by PBW 343. In millet, the amylose-amylopectin ratio was higher in finger millet followed by barnyard millet. The amylose-amylopectin ratio was found lower in foxtail millet and maximum in Pant Basmati 2 comparatively to all cultivars.

\section{Study of starch by SEM analysis}

The morphological properties of starch granules were studied by scanning electron microscope. Scanning electron microscopy (SEM) has been a useful tool for investigating the microstructures of cereal grains and derived products (Orth et al., 1973a, b; Fannon et al., 1993; Gallant et al., 1997). The variation in size and shape of starch granules may be due to their biological origin (Svegmark and Hermansson, 1993). The morphology of starch granules also depends on the biochemistry of the chloroplast or amyloplast as well as physiology of the plant (Badenhuizen, 1969). The scanning images of starch granules of barnyard millet ${ }^{\AA \mathrm{B} C}$, finger 
millet D E F and foxtail millet ${ }^{\mathrm{GH}}{ }^{\mathrm{I}}$ shown in figure 2 at $500 \mathrm{X}^{\mathrm{AD} \mathrm{G}}, 1000 \mathrm{X}^{\mathrm{B} \mathrm{E} \mathrm{H}}$ and $2000 \mathrm{X}$ $\mathrm{CFI}$. The scanning images of starch granules of wheat (UP262 ${ }^{A B}$ C $P B W 343^{D E}$ ) shown in figure 3 at $500 \mathrm{X}^{\mathrm{AD}}, 1000 \mathrm{X}^{\mathrm{B} \mathrm{E}}$ and $2000 \mathrm{X}^{\mathrm{C} F}$. The scanning images of starch granules of rice (PB $2^{\mathrm{A} \mathrm{B} \mathrm{C}} \mathrm{PD} 19^{\mathrm{D} \mathrm{E} \mathrm{F}}$ ) shown in figure 4 at 500X ${ }^{\mathrm{A} \mathrm{D}}, 1000 \mathrm{X}^{\mathrm{B} \mathrm{E}}$ and 2000X ${ }^{\mathrm{C} F}$. Barnyard millet starch showed large spherical, small polygonal and small spherical shaped granules. Large spherical granules showed relatively smooth surfaces with depressions or indentations due to protein bodies. The size of granules ranged from $6.46 \mu \mathrm{m}-12.23 \mu \mathrm{m}$. Finger millet starch granules are mostly polygonal and the granules size range from 4.60-9.19 $\mu \mathrm{m}$. Small granules are also present but larger granules were present in higher numbers. The size of granules is smaller than barnyard millet. Foxtail millet starch granules are small spherical and polygonal. Granules size is comparatively smaller than finger and barnyard millet.

The granule size ranges from 4.6-12.02 $\mu \mathrm{m}$. Malleshi et al., (1986) reported that finger millet starch contained granules of uneven shape spherical, polygonal and rhombic. Hard endosperm of corn has been shown to have nearly polygonal starch granules, whereas the soft endosperm has nearly round granules (Robutti et al., 1974). Pant Basmati 2 starch granules are large irregular and the size range from $30.22 \mu \mathrm{m}-177.13 \mu \mathrm{m}$. Pant Dhan 19 starch granules are small and large asymmetrical shape with size range from $6.22 \mu \mathrm{m}-110.95 \mu \mathrm{m}$.

The cultivars used in the study vary from small to large granules. Small granules $(<10$ $\mu \mathrm{m})$ bind more water increases dough stiffness and reduces the elasticity. From the morphology study of starch granules finger millet imparts increased dough stiffness and reduce elasticity. Millet starch binds more water comparatively to wheat and rice starch. Similar result was reported by Huang and Lai
(2010).The native starches of different rice cultivars consisted of mixed population of large, medium and small granules with the diameter range of $10 \mu \mathrm{m}-150 \mu \mathrm{m}$. The small granules were spherical or ellipsoidal while the medium and large granules were ellipsoidal to irregular or cubical in shape. Basmati starch granules has a intact structure having crystalline surface with pores on some parts of the granules, while other rice starch granules has loose structure with highly rough surface. This irregular rough surface of the granules was due to damage of starch during isolation process (Reddy and Bhotmange, 2013). Bhattacharya (2012) reported that rice starch with small starch granule sizes are suitable ingredient for extruded snack. Pure wheat starch had smooth-walled pores, while an addition of gluten resulted in pores with roughened and torn pore walls (Philipp et al., 2017). Moin et al., (2017) reported that the granular size for both rice varieties ranged between (4.5-7.05) $\mathrm{mm}$.

Rice starch granules for both rice varieties (Basmati and Irri rice) were found to be polygonal and irregular in shape. Singh et al., (2006) reported smaller sizes (1.5-5.8) $\mathrm{mm}$ for starches isolated from Indian rice cultivars. However, the shape was irregular, similar to what observed in the present study. Native starches have shiny surface, however due to erosion, starches often clump together and appear in form of clusters.

This phenomenon was found to be more pronounced for rice starches treated with 0.8 $\mathrm{M} \mathrm{HCl}$ (Hu et al., 2014). UP262 starch granules are small and large spherical with size ranges from $2.56 \mu \mathrm{m}-25.92 \mu \mathrm{m}$ while PBW343 contained starch granules of anomalous shape with size ranges from 32.2 $\mu \mathrm{m}-198.23 \mu \mathrm{m}$. The different sizes of the starch granules might be attributed to their different time of formation during grain development (Xie et al., 2008). 
Table.1 Proximate analysis of starch yield, amylose content, total starch and amylose -amylopectin ratio

\begin{tabular}{|c|c|c|c|c|c|c|}
\hline $\begin{array}{l}\text { Serial } \\
\text { no }\end{array}$ & Cultivars & $\begin{array}{l}\text { Starch yield } \\
\qquad(\%)^{1}\end{array}$ & $\begin{array}{c}\text { Amylose } \\
\text { content }(\%)^{2}\end{array}$ & $\begin{array}{l}\text { Total starch } \\
\text { content }(\%)^{3}\end{array}$ & Amylopectin ${ }^{4}$ & $\begin{array}{l}\text { Amylose/ } \\
\text { Amylopectin }\end{array}$ \\
\hline 1 & $\begin{array}{l}\text { Barnyard Millet (VL Madira- } \\
\text { 207) }\end{array}$ & $35.6 \pm .88^{\mathrm{d}}$ & $33.33 \pm 1.14^{b c}$ & $58.56 \pm 0.43^{\mathrm{cd}}$ & $66.67 \pm 1.14$ & 0.50 \\
\hline 2 & $\begin{array}{l}\text { Finger Millet (VL Mandua- } \\
\text { 352) }\end{array}$ & $37.6 \pm 1.45^{\mathrm{cd}}$ & $35.10 \pm 1.81^{b}$ & $57.25 \pm 0.08^{d}$ & $64.9 \pm 1.81$ & 0.54 \\
\hline 3 & Foxtail millet (DHFT-109-3) & $37.6 \pm 1.45^{\mathrm{cd}}$ & $31.33 \pm 0.78^{c}$ & $59.62 \pm 0.28^{\mathrm{cd}}$ & $68.67 \pm 0.78$ & 0.46 \\
\hline 4 & Wheat (UP 262) & $41.0 \pm 2.08^{b c}$ & $43.16 \pm 0.56^{\mathrm{a}}$ & $63.61 \pm 0.22^{b}$ & $54.57 \pm 0.12$ & 0.76 \\
\hline 5 & Wheat (PBW343) & $39.3 \pm 1.76^{\mathrm{cd}}$ & $35.76 \pm 0.63^{b}$ & $60.34 \pm 0.11^{\mathrm{c}}$ & $56.23 \pm 0.26$ & 0.56 \\
\hline 6 & Rice (Pant Basmati 2) & $48.0 \pm 1.73^{\mathrm{a}}$ & $45.43 \pm 0.12^{\mathrm{a}}$ & $67.94 \pm 1.04^{\mathrm{a}}$ & $56.83 \pm 0.56$ & 0.83 \\
\hline 7 & Rice (Pant Dhan 19) & $44.3 \pm 1.20^{\mathrm{ab}}$ & $43.76 \pm 0.26^{\mathrm{a}}$ & $70.68 \pm 2.21^{\mathrm{a}}$ & $64.23 \pm 0.63$ & 0.78 \\
\hline
\end{tabular}


Table.2 Structural characteristics of different cultivars starches as determined by IR ratio

\begin{tabular}{|l|l|l|l|}
\hline S. No & Cultivars & $1047 / 1022$ & $1022 / 995$ \\
\hline 1 & Barnyard Millet (VL Madira-207) & 1.00 & 1.13 \\
\hline 2 & Finger Millet (VL Mandua-352) & 1.02 & 1.19 \\
\hline 3 & Foxtail millet (DHFT-109-3) & $\mathbf{0 . 9 4}$ & 1.07 \\
\hline 4 & Wheat (UP 262) & 1.24 & $\mathbf{0 . 9 3}$ \\
\hline 5 & Wheat (PBW343) & 1.00 & $\mathbf{0 . 8 8}$ \\
\hline 6 & Rice (Pant Basmati 2) & $\mathbf{1 . 0 2}$ & $\mathbf{0 . 8 9}$ \\
\hline 7 & Rice (Pant Dhan 19) & $\mathbf{0 . 9 9}$ & $\mathbf{0 . 9 5}$ \\
\hline
\end{tabular}

Fig.1 Isolated starch from different cereals likes millet (Barnyard millet ${ }^{\mathrm{A}}$, Finger millet ${ }^{\mathrm{B}}$, and Foxtail millet ${ }^{\mathrm{C}}$ ), wheat $\left(\mathrm{UP} 262^{\mathrm{D}}, \mathrm{PBW}{ }^{\mathrm{E}}{ }^{\mathrm{E}}\right.$ ) and rice (Pant Basmati $2^{\mathrm{F}}$, Pant Dhan $19^{\mathrm{G}}$ )

Millets
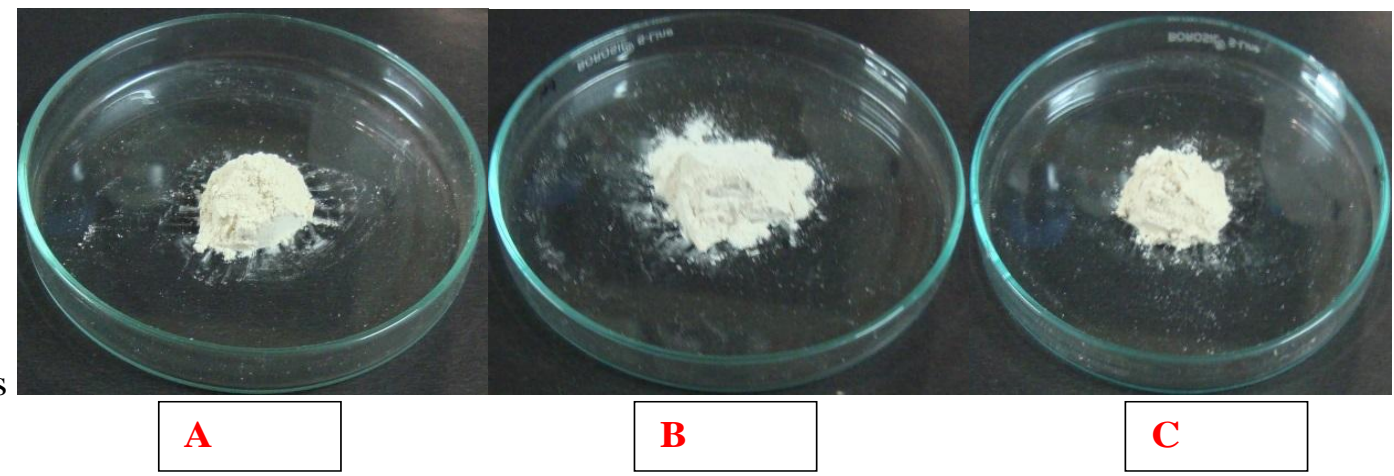

C

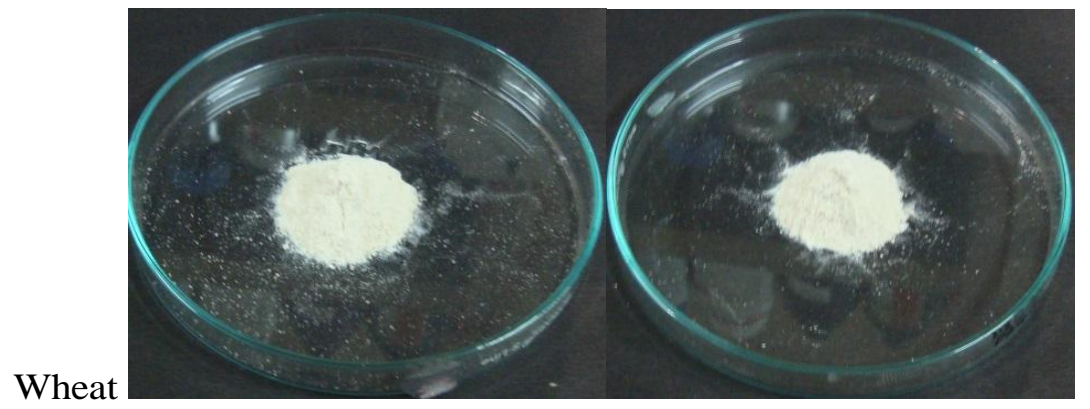

Wheat
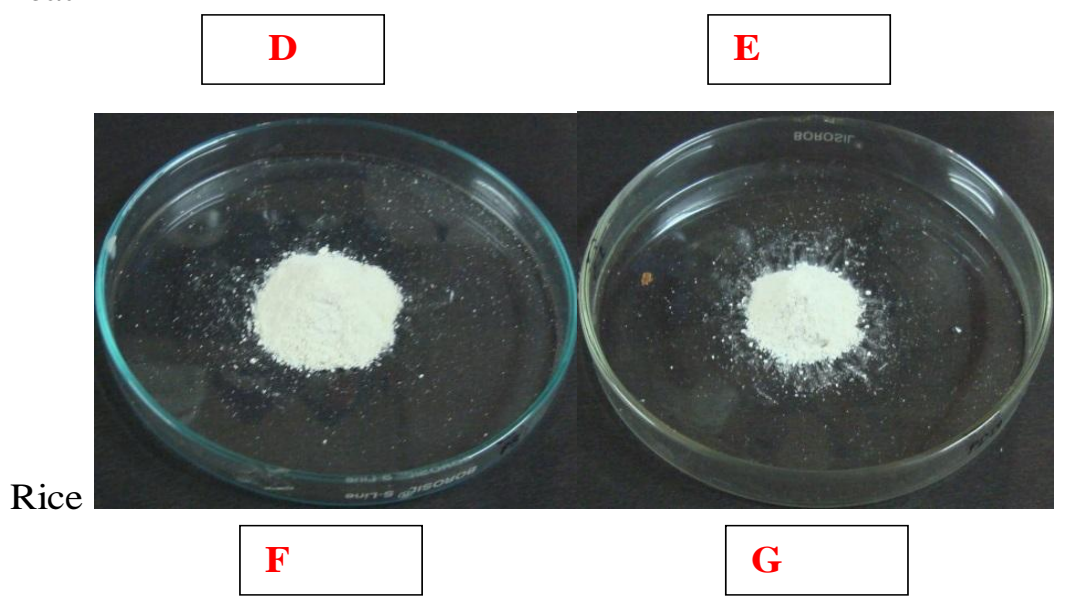
Fig.2 Scanning electron microscope images of millets (Barnyard millet ${ }^{\mathrm{ABC}}{ }^{\mathrm{C}}$ Finger millet ${ }^{\mathrm{DE}} \mathrm{F}$ Foxtail millet $\left.{ }^{\mathrm{GHI}}\right)$ at $500 \mathrm{X}^{\mathrm{A} \mathrm{D} \mathrm{G}}, 1000 \mathrm{X}^{\mathrm{BEH}}$ and $2000 \mathrm{X}^{\mathrm{C} \mathrm{F} \mathrm{I}}$
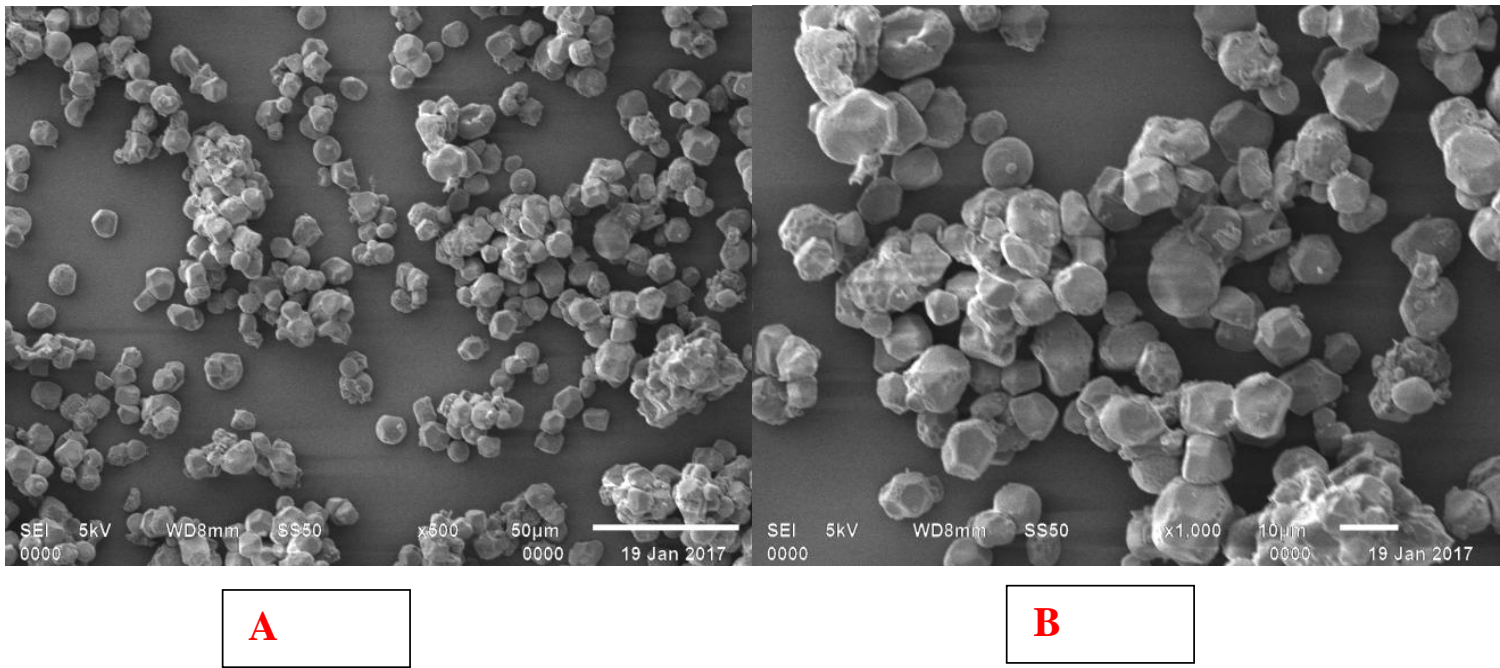

B

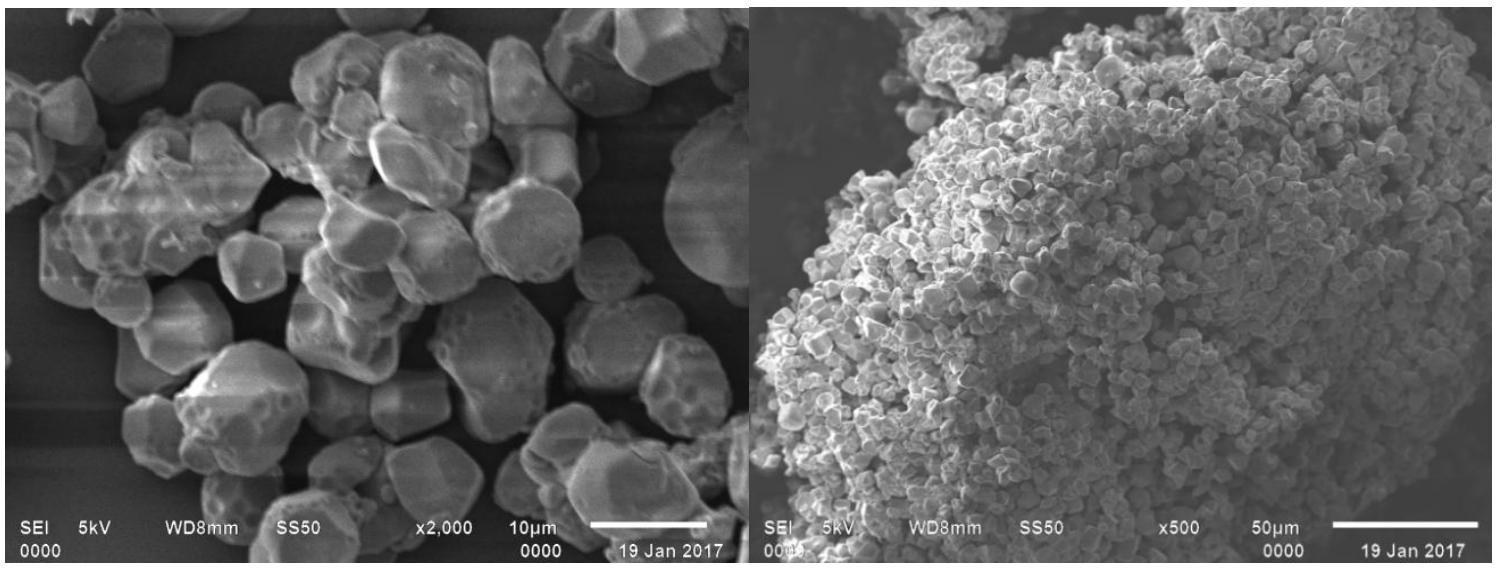

C

D

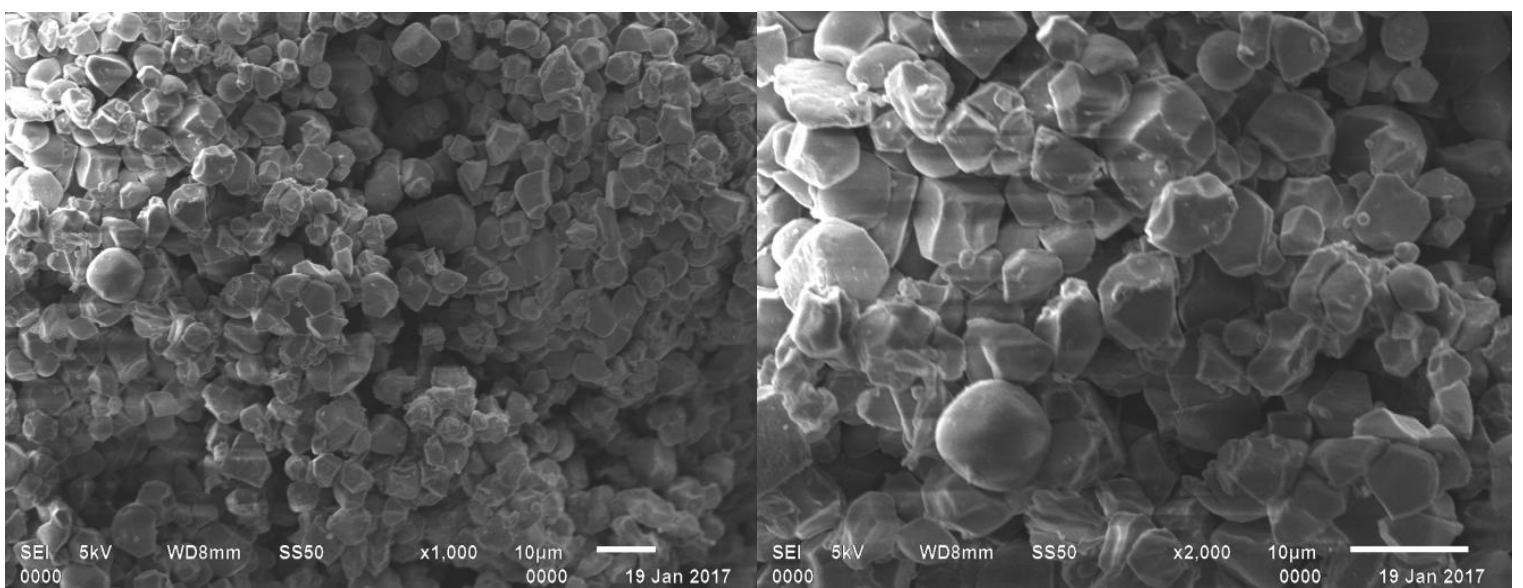

$\mathbf{E}$

F 
Int.J.Curr.Microbiol.App.Sci (2018) 7(10): 211-228
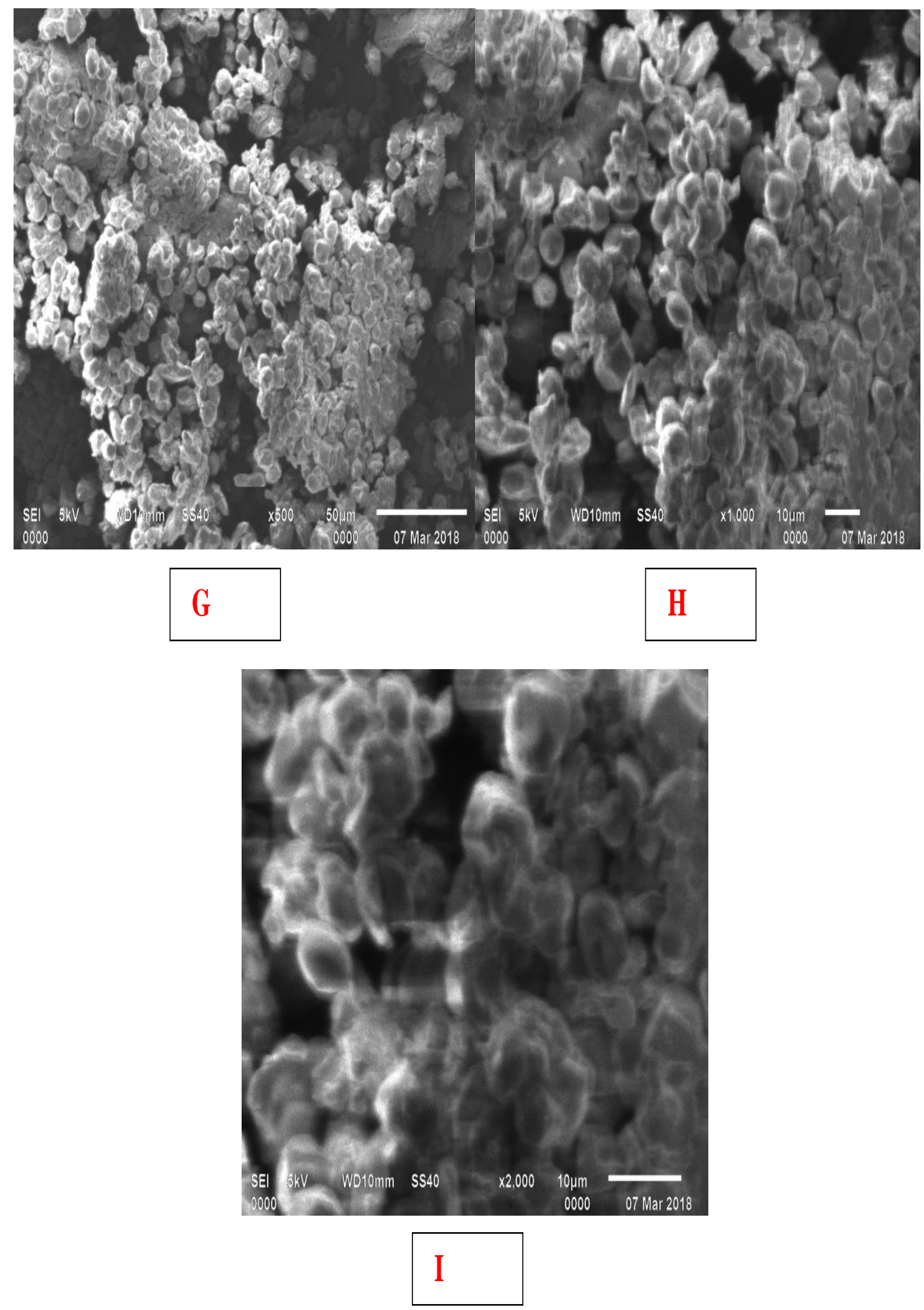
Fig.3 Scanning electron microscope images of wheat (UP262 ${ }^{\mathrm{A} \mathrm{B} \mathrm{C}} \mathrm{PBW} 343^{\mathrm{D} \mathrm{E} \mathrm{F}}$ ) at $500 \mathrm{X}^{\mathrm{AD}}$, $1000 X^{\mathrm{BE}}$ and $2000 \mathrm{X}^{\mathrm{C} F}$
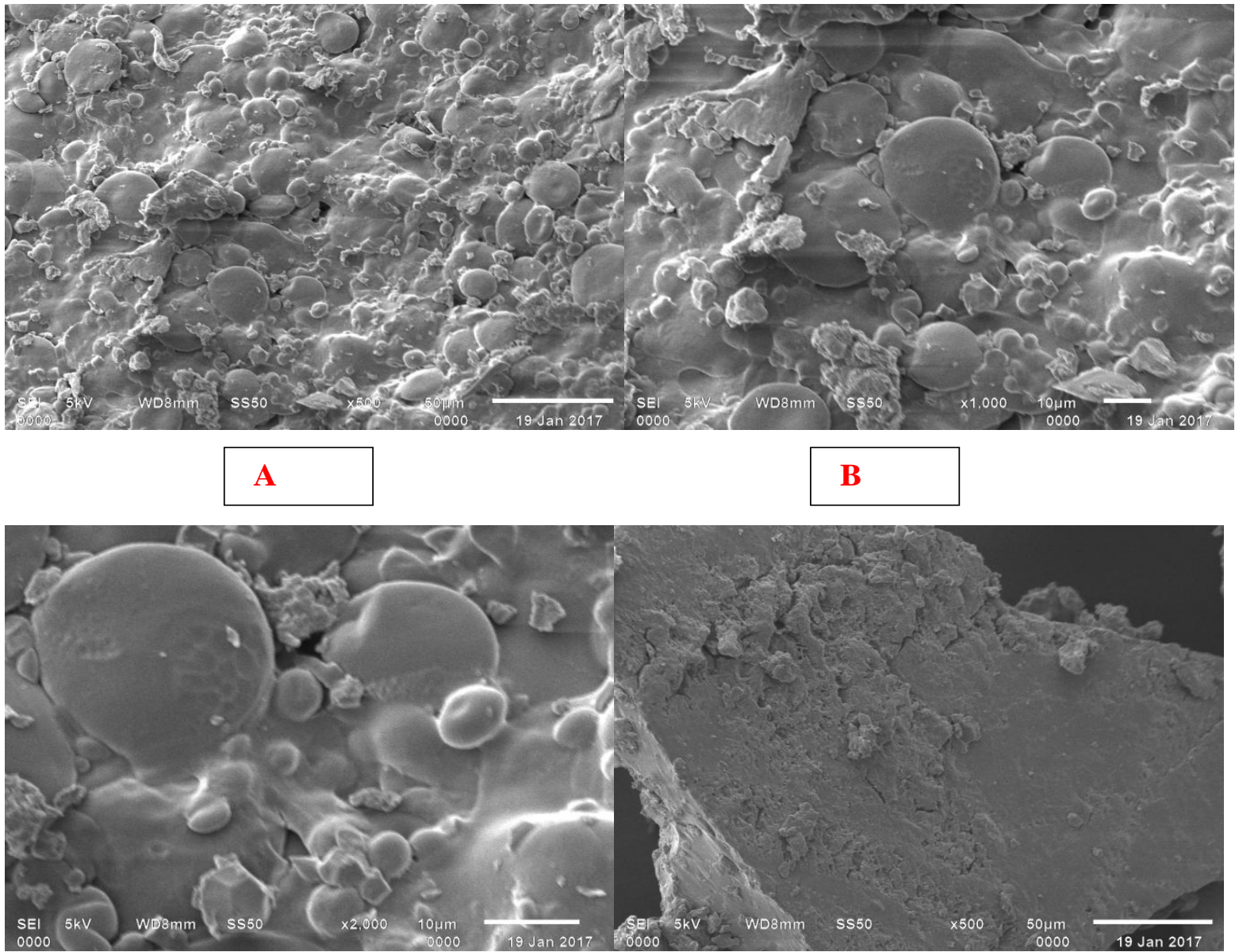

C

D

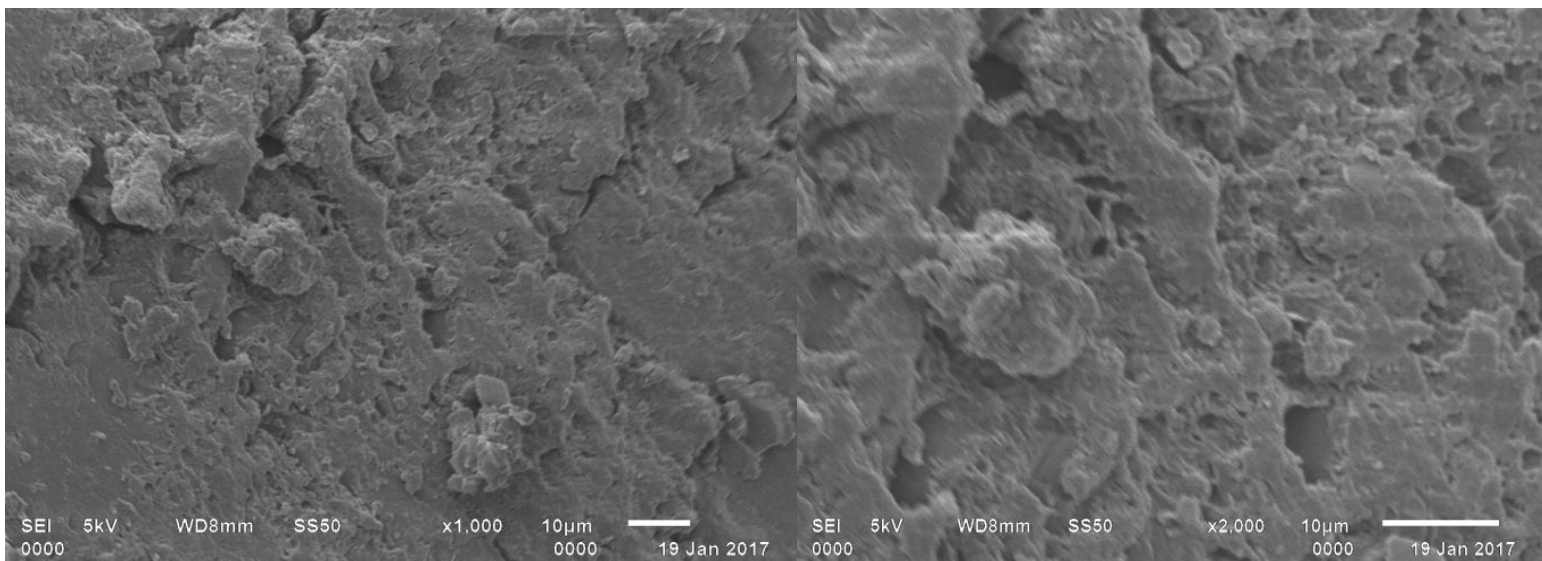

$\mathbf{E}$ 
Fig.4 Scanning electron microscope images of rice (Pant Basmati $2{ }^{\mathrm{A} \mathrm{B} \mathrm{C}}$ Pant Dhan $19^{\mathrm{DE}}$ ) at $150 \mathrm{X}^{\mathrm{AD}}, 300 \mathrm{X}^{\mathrm{BE}}$ and $500 \mathrm{X}^{\mathrm{CF}}$
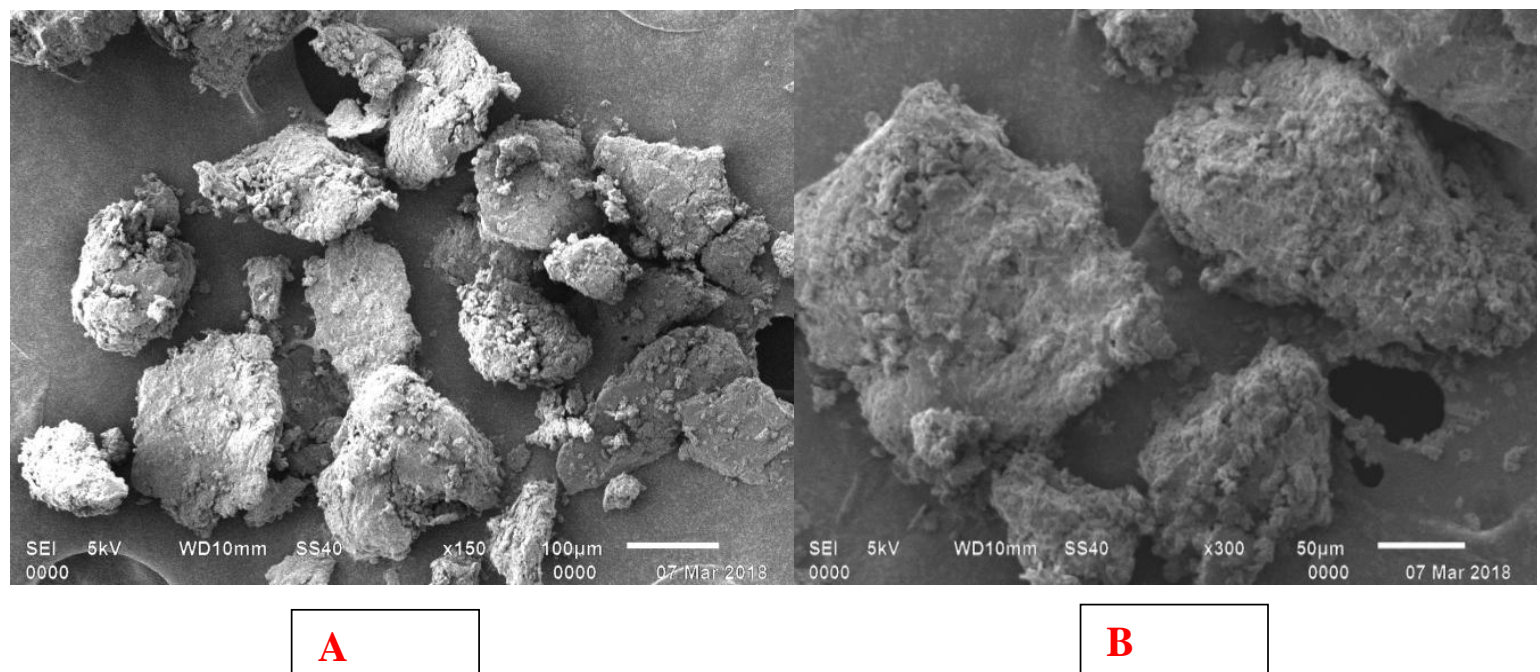

B

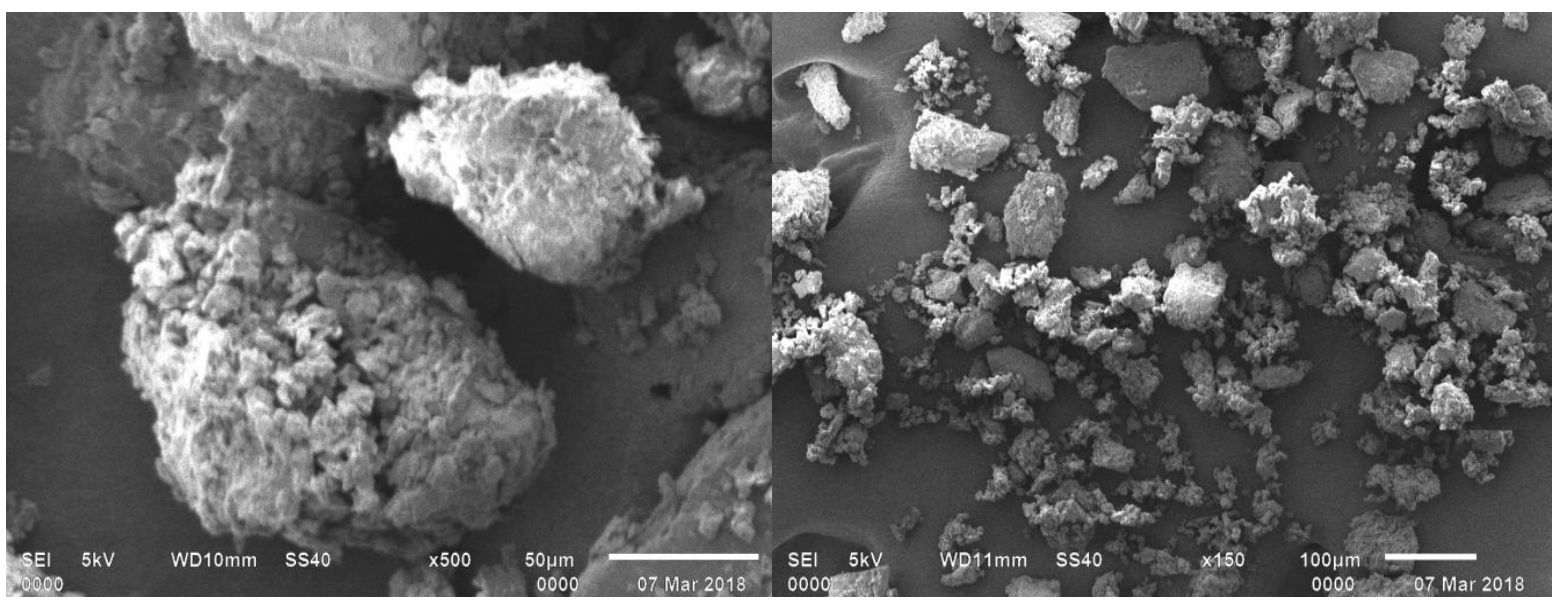

C

D



E 
Fig.5 FTIR spectra of millets starch (Barnyard millet, Finger millet, Foxtail millet)

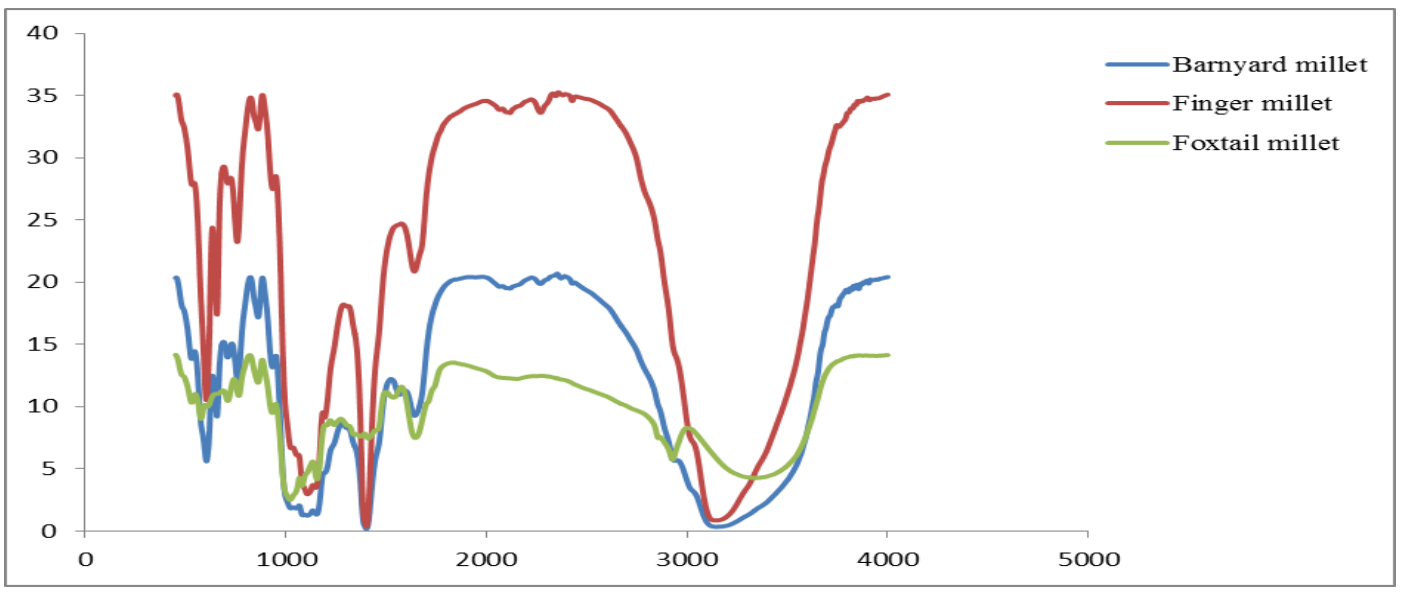

Fig.6 FTIR spectra of Wheat starch (UP262, PBW343)

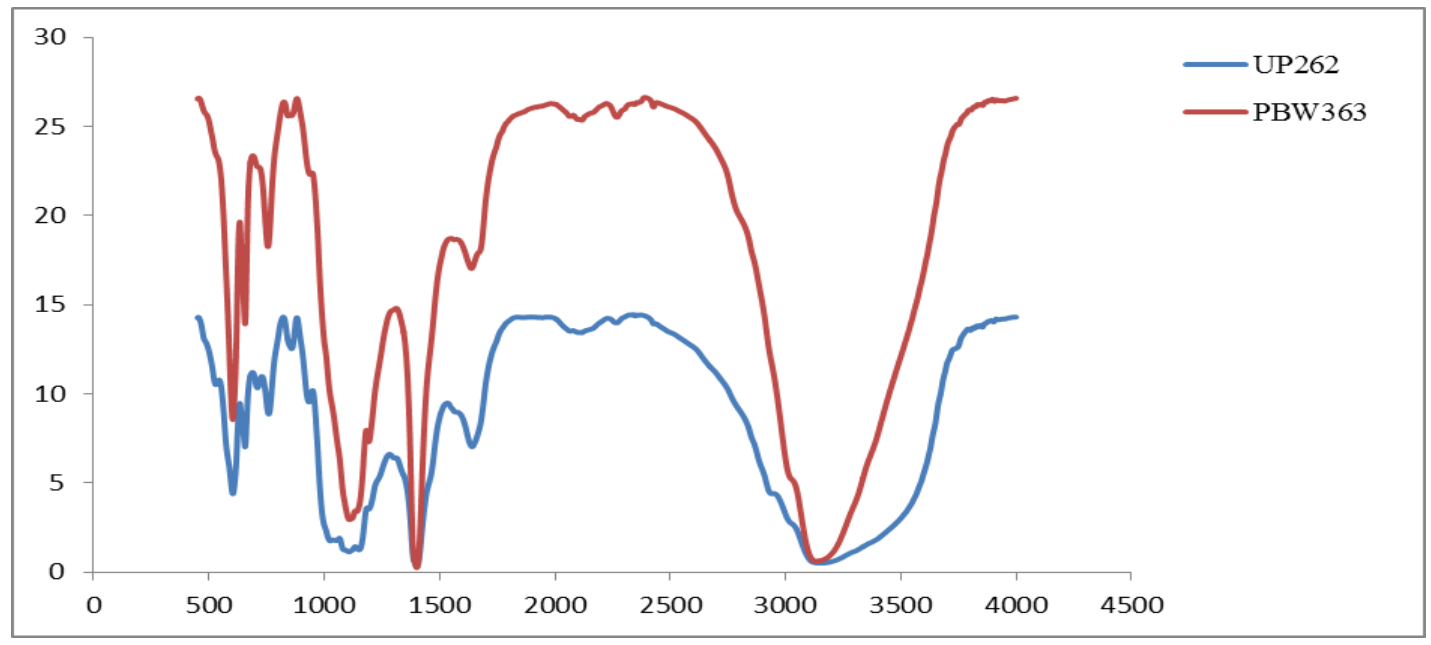

Fig.7 FTIR spectra of Rice starch (Pant Basmati 2 and Pant Dhan 19)

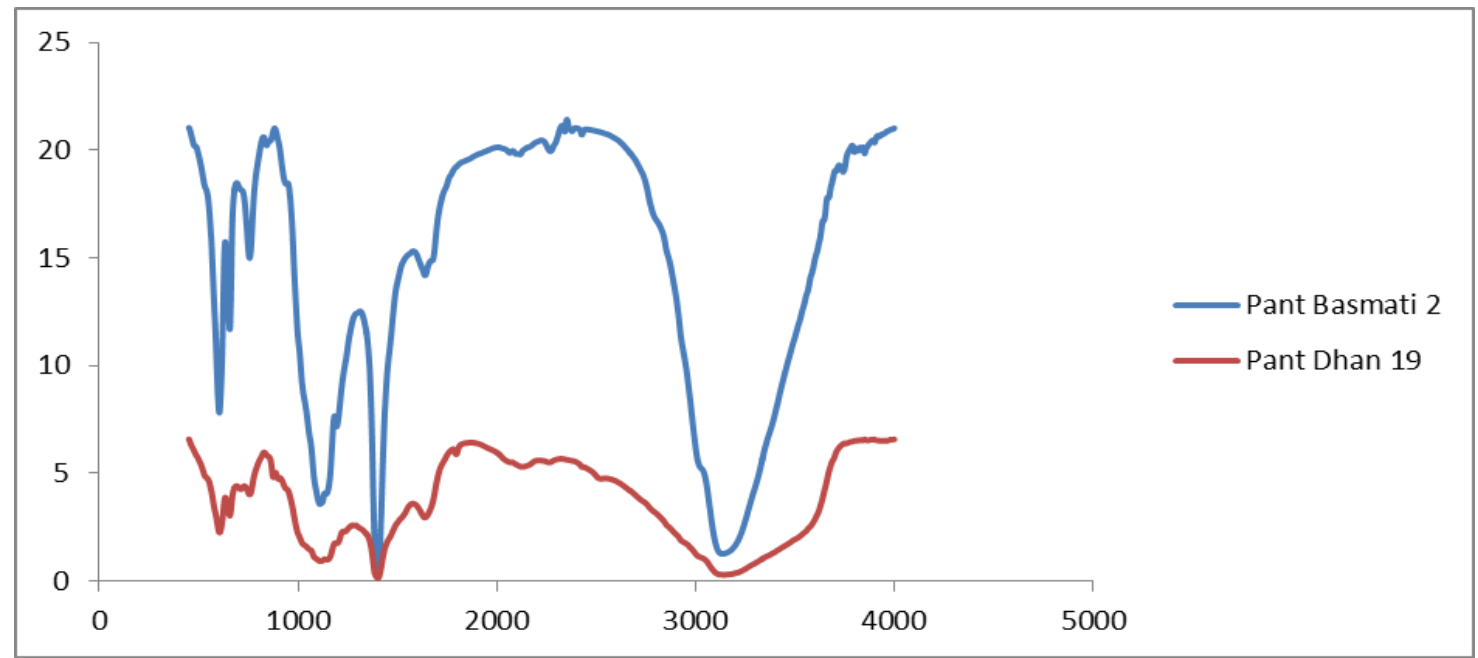


Karwasra et al., (2017) observed that wheat contains generally bimodal size distribution of starch granule populations and has two types of size groups e.g. small granules (below 10 $14 \mu \mathrm{m}$ ), large granules (above $10-14 \mu \mathrm{m}$ to $36 \mu \mathrm{m}$ ) and the larger A-type wheat starch granules were generally disc like or lenticular while the smaller B-type granules were spherical and somewhat polygonal in shape. Similar spherical and irregular shapes for Btype starch granules were also observed by Zhang et al., (2013). SEM also revealed that some starch granules were not intact and they were broken into half or more divisions. The damaged starch amount depends on the severity of grinding and the hardness of wheat grains (Hoseney, 1994).

\section{FT-IR spectra of starch}

The infrared spectroscopy is sensitive to structural changes on starch macromolecule, such as helicoidal chain conformation, crystallinity, retrogradation and water content (Kumar and Khatkar, 2017). Amir et al., (2011) observed that the FTIR spectra of starch showed broad absorption between $3000-3600 \mathrm{~cm}^{-1}$ and $1500-1700 \mathrm{~cm}^{-1}$ due to stretching frequency of the $-\mathrm{OH}$ group and $\mathrm{C}-\mathrm{H}$ group, respectively. The major absorption bands of starch observed in between 1000-1200 $\mathrm{cm}^{-1}$, arising from $\mathrm{C}-\mathrm{O}$, $\mathrm{C}-\mathrm{C}$, and $\mathrm{C}-\mathrm{O}-\mathrm{H}$ stretching and $\mathrm{C}-\mathrm{O}-\mathrm{H}$ bending, were similar to absorption band observed by Warren et al., (2016). The IR spectrums of wheat starches were described by three main regions, with maximum absorbance peaks near 3500-2400, 17001000, 1000-400 $\mathrm{cm}^{-1}$ (Yoo and Jane 2002; Jane et al., 1994). The FTIR spectra of isolated starch from different cereals like millets (Fig. 5), wheat (Fig. 6), rice (Fig. 7) showed peaks at 3100-3400 and 2200-3000 $\mathrm{cm}^{-1}$ corresponding to $\mathrm{O}-\mathrm{H}$ stretching due to hydrogen-bonded hydroxyl groups and the $\mathrm{C}$ $\mathrm{H}$ deformation of the glucose unit, respectively, while the peaks at 1400.99 and $1366 \mathrm{~cm}^{-1}$ were attributable to the bending modes of $\mathrm{H}-\mathrm{C}-\mathrm{H}, \mathrm{C}-\mathrm{H}$ and $\mathrm{O}-\mathrm{H}$. The peaks at $1300-1000 \mathrm{~cm}^{-1}$ were attributed to $\mathrm{C}-\mathrm{O}-\mathrm{H}$ stretching with some attribute to $\mathrm{C}-\mathrm{C}$ stretching. The peaks at $1193-1109 \mathrm{~cm}^{-1}$ were attributed to $\mathrm{C}-\mathrm{O}-\mathrm{H}$ stretching with some attribute to $\mathrm{C}-\mathrm{C}$ stretching in $\mathrm{PB} 2$. A peak ranging between $840 \mathrm{~cm}^{-1}$ to $875 \mathrm{~cm}^{-1}$ was observed in all samples except PB2 was associated to $\mathrm{C}-\mathrm{H}$ of residual carbon (FreilePelegrín et al., 2007). These results were similar to starch characterization using FTIR by Correia et al., (2012), Luo et al., (2009) and $\mathrm{Wu}$ et al., (2009). The peaks at 1191.931151 and $1080-1106 \mathrm{~cm}^{-1}$ were contributed to $\mathrm{C}-\mathrm{OH}$ and $\mathrm{CH}_{2}$ deformations. The bands at 1051.92 and $1022 \mathrm{~cm}^{-1}$ were associated with the ordered and amorphous structures of starches, respectively. The bands at 933.78$900 \mathrm{~cm}^{-1}$ were attributed to D-glucopyranosyl ring vibrational modes, $861 \pm 10 \mathrm{~cm}^{-1}$ to the $\mathrm{C}-\mathrm{H}$ absorbance of the D-glucopyranosyl rings and $759.52 \pm 10 \mathrm{~cm}^{-1}$ to $\mathrm{D}$ glucopyranosyl ring stretching. The 1641.94$1566 \mathrm{~cm}^{-1}$ bands were assigned to the bending vibration of $\mathrm{O}-\mathrm{H}$ of water absorbed in the amorphous regions of starch. In the present study it was observed that the moisture content of finger millet was found higher followed by barnyard millet and foxtail millet. Similar results were presented by the Zeng $e t$ al., (2011). Bands at $1053 \mathrm{~cm}^{-1}$ increases with the storage time due to the crystallization of starch chains (Good fellow and Wilson 1990). The absorbance ratios of $1047 / 1022$ and $1022 / 995 \mathrm{~cm}^{-1}$ are the indexes of the shortrange order of double helices (Sevenou et al., 2002). IR bands at $1047 \mathrm{~cm}^{-1}$ and $1022 \mathrm{~cm}^{-1}$ are associated with ordered and amorphous structure of starch respectively (Kumar and Khatkar 2017). The ratio of absorbance $1047 / 1022 \mathrm{~cm}^{-1}$ was used to quantify the degree of order in starch samples. The absorbance ratios of 1047/1022 and 1022/995 $\mathrm{cm}-1$ are represented in Table 2 . In the 
present investigation the maximum short range order of helices was found in wheat (UP 262) followed by Pant Basmati 2. The short range order of helices was found similar in (Pant Basmati 2 and finger millet), (PBW 343 and barnyard millet). It was concluded that short range order of helices in cereals like millet, rice and wheat were approximately similar.

\section{Acknowledgement}

Authors are grateful to Dept. of Biochemistry, Plant Breeding and Genetics, Agronomy GBPUA\&T, Pantnagar to carry out this research work. Our sincere thanks to DSTFIST for providing equipment facility and Directorate of Experiment Station (DES) Pantnagar for utilization of infrastructure.

\section{References}

Amir, R. M., Anjum, F. M., Khan, M. I., Khan, M. R., Pasha, I., and Nadeem, M. (2013). Application of Fourier transform infrared (FTIR) spectroscopy for the identification of wheat varieties. Journal of food science and technology, 50(5), 1018-1023.

Badenhuizen, N. P. (1969). The biogenesis of starch granules in higher plants (No. QK887 B3).

Bhattacharya, S. (2011). Raw materials for extrusion of foods. Advances in Food Extrusion Technology, 69-87.

Blazek, J., and Copeland, L. (2008). Pasting and swelling properties of wheat flour and starch in relation to amylose content. Carbohydrate polymers, 71(3), 380-387.

Chen, Z., Schols, H. A., and Voragen, A. G. J. (2003). Starch granule size strongly determines starch noodle processing and noodle quality. Journal of Food Science, 68(5), 1584-1589.
Chmelik, J., Krumlová, A., Budinská, M., Kruml, T., Psota, V., Bohacenko, I., and Vydrová, H. (2001). Comparison of size characterization of barley starch granules determined by electron and optical microscopy, low angle laser light scattering and gravitational field- flow fractionation. Journal of the Institute of Brewing, 107(1), 11-17.

Copeland, L., Blazek, J., Salman, H., and Tang, M. C. (2009). Form and functionality of starch. Food hydrocolloids, 23(6), 1527-1534.

Correia, P., Cruz-Lopes, L., and Beirão-daCosta, L. (2012). Morphology and structure of chestnut starch isolated by alkali and enzymatic methods. Food Hydrocolloids, 28(2), 313-319.

Devi, P. B., Vijayabharathi, R., Sathyabama, S., Malleshi, N. G., and Priyadarisini, V. B. (2014). Health benefits of finger millet (Eleusine coracana L.) polyphenols and dietary fiber: a review. Journal of food science and technology, 51(6), 1021-1040.

Dipnaik, K., and Kokare, P. (2017). Ratio of Amylose and Amylopectin as indicators of glycaemic index and in vitro enzymatic hydrolysis of starches of long, medium and short grain rice. International Journal of Research in Medical Sciences, 5(10), 4502-4505.

Dubois, M., Gilles, K. A., Hamilton, J. K., Rebers, P. T., and Smith, F. (1956). Colorimetric method for determination of sugars and related substances. Analytical chemistry, 28(3), 350-356.

Edwards, N. M., Dexter, J. E., and Scanlon, M. G. (2002). Starch participation in durum dough linear viscoelastic properties. Cereal Chemistry, 79(6), 850-856.

Evers, A. D. (1973). The size distribution among starch granules in wheat endosperm. Starch-Stärke, 25(9), 303304. 
Fannon, J. E., and BeMiller, J. N. (1992). Structure of corn starch paste and granule remnants revealed by lowtemperature scanning electron microscopy after cryopreparation. Cereal Chem, 69(4), 456-460.

Fannon, J. E., Hauber, R. J., and BeMILLER, J. N. (1992). Surface pores of starch granules. Cereal Chem, 69(3), 284-288.

Fannon, J. E., Hauber, R. J., and BeMiller, J. N. (1992). Use of low-temperature scanning electron microscopy to examine starch granule structure and behavior. Frontiers in carbohydrate research, 2, 1-23.

Fannon, J. E., Shull, J. M., and BeMILLER, J. N. (1993). Interior channels of starch granules. Cereal Chemistry, 70, 611611.

Fergason, V. (2000). High amylose and waxy corns.In Specialty Corns, Second Edition (pp. 75-96).CRC Press.

Frei, M., Siddhuraju, P., and Becker, K. (2003). Studies on the in vitro starch digestibility and the glycemic index of six different indigenous rice cultivars from the Philippines. Food Chemistry, 83(3), 395-402.

Freile-Pelegrín, Y., Madera-Santana, T., Robledo, D., Veleva, L., Quintana, P., and Azamar, J. A. (2007). Degradation of agar films in a humid tropical climate: Thermal, mechanical, morphological and structural changes. Polymer Degradation and Stability, 92(2), 244-252.

Gallant, D. J., Bouchet, B., and Baldwin, P. M. (1997). Microscopy of starch: evidence of a new level of granule organization. Carbohydrate polymers, 32(3-4), 177-191.

Gerrano, A. S., Labuschagne, M. T., van Biljon, A., and Shargie, N. G. (2014). Genetic variability among sorghum accessions for seed starch and stalk total sugar content. Scientia Agricola, 71(6), $472-479$.

Goodfellow, B. J., and Wilson, R. H. (1990). A Fourier transform IR study of the gelation of amylose and amylopectin. Biopolymers: Original Research on Biomolecules, 30(13-14), 1183-1189.

Hoover, R. (2001). Composition, molecular structure, and physicochemical properties of tuber and root starches: a review. Carbohydrate polymers, 45(3), 253-267.

Hoseney, R. C. (1994). Principles of cereal science and technology (No.Ed. 2). American Association of Cereal Chemists (AACC).

Hu, X., Li, H., Wei, B., Xu, X., Jin, Z., and Tian, Y. (2014). Hydrolysis process of normal rice starch by 1-butanolhydrochloric acid. Food Hydrocolloids, 41, 27-32.

Huang, Y. C., and Lai, H. M. (2010). Noodle quality affected by different cereal starches. Journal of Food Engineering, 97(2), 135-143.

Jane, J. L., Kasemsuwan, T., Leas, S., Zobel, H., and Robyt, J. F. (1994). Anthology of starch granule morphology by scanning electron microscopy. Starch - Stärke, 46(4), 121-129.

Jobling, S. (2004). Improving starch for food and industrial applications. Current opinion in plant biology, 7(2), 210-218.

Karwasra, B. L., Gill, B. S., and Kaur, M. (2017). Rheological and structural properties of starches from different Indian wheat cultivars and their relationships. International Journal of Food Properties, 20(sup1), S1093S1106.

Kim, H. S., and Huber, K. C. (2008). Channels within soft wheat starch Aand B-type granules. Journal of Cereal Science, 48(1), 159-172.

Kim, S. K., Choi, H. J., Kang, D. K., and Kim, H. Y. (2012). Starch properties of 
native proso millet (Panicum miliaceum L.). Agronomy Research, 10(1-2), 311318.

Kumar, R., and Khatkar, B. S. (2017). Thermal, pasting and morphological properties of starch granules of wheat (Triticum aestivum L.) varieties. Journal of food science and technology, 54(8), 2403-2410.

Li, H., Prakash, S., Nicholson, T. M., Fitzgerald, M. A., and Gilbert, R. G. (2016).The importance of amylose and amylopectin fine structure for textural properties of cooked rice grains. Food chemistry, 196, 702-711.

Lindeboom, N., Chang, P. R., and Tyler, R. T. (2004). Analytical, biochemical and physicochemical aspects of starch granule size, with emphasis on small granule starches: a review. Starch-Stärke, 56(3- 4), 89-99.

Luo, F. X., Huang, Q., Fu, X., Zhang, L. X., and $\mathrm{Yu}$, S. J. (2009). Preparation and characterisation of crosslinked waxy potato starch. Food Chemistry, 115(2), 563-568.

Madsen, M. H., and Christensen, D. H. (1996). Changes in viscosity properties of potato starch during growth. Starch-Stärke, 48(7- 8), 245-249.

Malleshi, N. G., Desikachar, H. S. R., and Tharanathan, R. N. (1986). Physico- chemical properties of native and malted finger millet, pearl millet and foxtail millet starches. Starch-Stärke, 38(6), 202-205.

McCready, R. M., Guggolz, J., Silviera, V., and Owens, H. S. (1950).Determination of starch and amylose in vegetables. Analytical chemistry, 22(9), 1156-1158.

Moin, A., Ali, T. M., and Hasnain, A. (2017). Influence of different molar concentrations of acid on morphological, physicochemical and pasting properties of Pakistani Basmati and Irri rice starches. International journal of biological macromolecules, 101, 214-221.

Morrison, W. R., and Azudin, M. N. (1987). Variation in the amylose and lipid contents and some physical properties of rice starches. Journal of Cereal Science, 5(1), 35-44.

Oko, A. O., and Dambaba, N. (2012). Rice cooking quality and physico-chemical characteristics: a comparative analysis of selected local and newly introduced rice varieties in Ebonyi State, Nigeria. Food and Public Health, 2(1), 43-49.

Orth, R. A., Dronzek, B. L., and Bushuk, W. (1973). Scanning electron microscopy of bread wheat proteins fractionated by gel filtration. Cereal chemistry.

Orth, R. A., Dronzek, B. L., and Bushuk, W. (1973).Studies of glutenin. IV. Microscopic structure and its relations to breadmaking quality. Cereal chemistry.

Philipp, C., Oey, I., Silcock, P., Beck, S. M., and Buckow, R. (2017). Impact of protein content on physical and microstructural properties of extruded rice starch-pea protein snacks. Journal of Food Engineering, 212, 165-173.

Reddy, D. K., and Bhotmange, M. G. (2013). Isolation of starch from rice (Oryza sativa L.) and its morphological study using scanning electron microscopy. International Journal of Agriculture and Food Science Technology, 4(9), 859-866.

Robutti, J. L., Hoseney, R. C., and Wassom, C. E. (1974). Modified opaque-2 corn endosperms. II. Structure viewed with a scanning electron microscope. Cereal Chem, 51(2), 173-180.

Röper, H. (2002). Renewable raw materials in Europe - industrial utilisation of starch and sugar [1]. Starch-Stärke, 54(3- 4), 89-99.

Sahlström, S., Bråthen, E., Lea, P., and Autio, K. (1998). Influence of starch granule 
size distribution on bread characteristics. Journal of Cereal Science, 28(2), 157-164.

Sevenou, O., Hill, S. E., Farhat, I. A., and Mitchell, J. R. (2002). Organisation of the external region of the starch granule as determined by infrared spectroscopy. International Journal of Biological Macromolecules, 31(1-3), 79-85.

Shobana, S., Krishnaswamy, K., Sudha, V., Malleshi, N. G., Anjana, R. M., Palaniappan, L., and Mohan, V. (2013). Finger millet (Ragi, Eleusine coracana L.): a review of its nutritional properties, processing, and plausible health benefits. In Advances in food and nutrition research (Vol. 69, pp. 1-39). Academic Press.

Singh, N., Kaur, L., Sandhu, K. S., Kaur, J., and Nishinari, K. (2006). Relationships between physicochemical, morphological, thermal, rheological properties of rice starches. Food hydrocolloids, 20(4), 532-542.

Slattery, C. J., Kavakli, I. H., and Okita, T. W. (2000). Engineering starch for increased quantity and quality. Trends in plant science, 5(7), 291-298.

Srichuwong, S., Sunarti, T. C., Mishima, T., Isono, N., and Hisamatsu, M. (2005). Starches from different botanical sources I: Contribution of amylopectin fine structure to thermal properties and enzyme digestibility. Carbohydrate polymers, 60(4), 529-538.

Svegmark, K., and Hermansson, A. M. (1993). Microstructure and rheological properties of composites of potato starch granules and amylose: a comparison of observed and predicted structures. Food Structure, 12(2), 6.

Thebaudin, J. Y., Lefebvre, A. C., and Doublier, J. L. (1998). Rheology of starch pastes from starches of different origins: applications to starch-based sauces. LWT-Food Science and Technology, 31(4), 354-360.

Wang, T. L., Bogracheva, T. Y., and Hedley, C. L. (1998). Starch: as simple as A, B, C? Journal of Experimental Botany, 49(320), 481-502.

Warren, F. J., Gidley, M. J., and Flanagan, B. M. (2016). Infrared spectroscopy as a tool to characterise starch ordered structure - a joint FTIR-ATR, NMR, XRD and DSC study. Carbohydrate polymers, 139, 35-42.

$\mathrm{Wu}$, Y., Geng, F., Chang, P. R., Yu, J., and Ma, X. (2009). Effect of agar on the microstructure and performance of potato starch film. Carbohydrate Polymers, 76(2), 299-304.

Xie, X. S., Cui, S. W., Li, W., and Tsao, R. (2008). Isolation and characterization of wheat bran starch. Food Research International, 41(9), 882-887.

Yoo, S. H., and Jane, J. L. (2002). Structural and physical characteristics of waxy and other wheat starches. Carbohydrate Polymers, 49(3), 297-305.

Zeng, J., Li, G., Gao, H., and Ru, Z. (2011). Comparison of $\mathrm{A}$ and $\mathrm{B}$ starch granules from three wheat varieties. Molecules, 16(12), 10570-10591.

Zhang, B., Li, X., Liu, J., Xie, F., and Chen, L. (2013). Supramolecular structure of A-and B-type granules of wheat starch. Food Hydrocolloids, 31(1), 68-73.

\section{How to cite this article:}

Vivek Chandra Verma, Anil Kumar, M.G.H. Zaidi, A.K. Verma, J.P. Jaiswal, D.K. Singh, Archana Singh and Sanjeev Agrawal. 2018. Starch Isolation from Different Cereals with Variable Amylose/Amylopectin Ratio and Its Morphological Study Using SEM and FT-IR. Int.J.Curr.Microbiol.App.Sci. 7(10): 211-228. doi: https://doi.org/10.20546/ijcmas.2018.710.022 